\title{
Generalized anxiety and depressive symptoms in various age groups during the COVID-19 lockdown. Specific predictors and differences in symptoms severity
}

Małgorzata Gambin(1), Marcin Sękowski(2)*, Małgorzata Woźniak-Prus(2)*, Anna

Wnuk(3), Tomasz Oleksy(1), Andrzej Cudo(4), Karolina Hansen(1), Mirosława HuflejtŁukasik(1), Karolina Kubicka(1), Agnieszka Ewa Łyś(1), Joanna Gorgol(1), Paweł Holas(1), Grażyna Kmita(1), Emilia Lojek(1), Dominika Maison(1)

*These authors have equal contribution to this work.

1) Department of Psychology, University of Warsaw, ul Stawki 5/7, 00-183 Warsaw, Poland

2) Institute of Psychology, The Maria Grzegorzewska University, ul. Szczęśliwicka 40 02-353 Warsaw, Poland

3) The Robert Zajonc Institute for Social Studies, University of Warsaw, ul Stawki 5/7, 00-183 Warsaw, Poland

4) Faculty of Social Sciences, The John Paul II Catholic University of Lublin

Corresponding author: Malgorzata Gambin, Department of Psychology, University of Warsaw, ul. Stawki 5/7,00-183 Warsaw, Poland,mgambin@psych.uw.edu.pl;

The publication is financed by the funds from the Faculty of Psychology at the University of

Warsaw awarded by the Polish Ministry of Science and Higher Education in the form of a subvention for maintaining and developing research potential in 2020.

Conflict of Interest: The authors declare that they have no conflict of interest. 


\begin{abstract}
Background. Previous studies carried out in different countries indicated that young adults experience higher levels of depressive and anxiety symptoms than older age groups during the COVID-19 pandemic. However, little is known about which epidemic-related difficulties and factors may contribute to these forms of emotional distress in various age groups. Purpose. The aim of the current study was to investigate: (i) differences in levels of depressive and generalized anxiety symptoms, as well as perceived difficulties related to pandemic across four age groups in the Polish population; (ii) which factors and difficulties related to pandemic are predictors of generalized anxiety and depressive symptoms in various age groups during the COVID-19 lockdown. Method. A total of 1115 participants (aged 18-85) took part in the study. The group was a representative sample of the Polish population in terms of sex, age, and place of residence. Participants completed online: The Patient Health Questionnaire-9, The Generalized Anxiety Disorder-7, Scale of Perceived Health and Life Risk of COVID-19, Social Support Sale, Scale of Epidemic-Related Difficulties. Results. Younger age groups (18-29 and 30-44) experienced higher levels of depressive and generalized anxiety symptoms than older adults (45-59 and 60-85 years). Difficulties in relationships and at home were amongst the strongest predictors of depressive and generalized anxiety symptoms in all age groups. Fear and uncertainty related to the spread of the virus were one of the most important predictors of emotional distress in all the groups apart from the adults between 18-29 years, whereas difficulties related to external restrictions were one of the most significant predictors of depressive and anxiety symptoms only in the youngest group. Conclusions. Our results indicate
\end{abstract}


that the youngest adults and those experiencing difficulties in relationships among household members were the most vulnerable to depressive and generalized anxiety symptoms during the COVID-19 lockdown. Thus, it is important to plan preventive and therapeutic interventions to support these at-risk individuals in dealing with the challenges related to the COVID-19 pandemic.

Key words: depressive symptoms, generalized anxiety symptoms, COVID-19 outbreak, lockdown, epidemic-related difficulties 


\section{Highlights}

- Higher levels of depressive and generalized anxiety symptoms were experienced by the younger adults (18-29 and 30-44 years) during the COVID-9 lockdown than by older adults (45-59 and 60-85 years).

- Factors and difficulties related to pandemic explained from 21\% (in 30-44 years group) to $24 \%$ (in 18-29 years groups) of variance of depressive symptoms, as well as from $21 \%$ (in the youngest group) to $31 \%$ (in the oldest group) of variance of generalized anxiety symptoms during the lockdown.

- Difficulties in relationships and household duties were one of the strongest predictors of depressive and generalized anxiety symptoms in all the age groups during the COVID-19 outbreak.

- Fear and uncertainty related to the spread of the virus were one of the most important predictors of depressive and generalized anxiety symptoms in all groups apart from the youngest adults (18-29 age) during the lockdown.

- Difficulties related to external restrictions were one of the most significant predictors of emotional distress only in the youngest adults during the COVID-19 outbreak. 
The COVID-19 pandemic is associated with threats to the health and life of people around the world (Anderson et al., 2020) and it leads to huge shifts in everyday functioning, many of which are perceived as negative change. A range of control strategies were established in many countries to reduce social mixing such as closure of schools, kindergartens and nurseries, remote working or movement restrictions. In mid-March, also a lockdown was imposed in Poland for six weeks confining people to their homes, except for essential activities. Threat to life, imposed restrictions and associated changes may contribute to the severe psychological distress, including symptoms of depression and generalized anxiety among the whole population (Asmundson \& Taylor, 2020; Duan \& Zhu, 2020). One of the crucial factors that can affect the severity of depressive and anxiety symptoms during the COVID-19 pandemic is the stage of development during the life span. At different periods of life, people face specific psychosocial tasks trying to meet dominant developmental needs and requirements (e.g. Erikson \& Erikson, 1997; Feldman, 2018; Peterson, 2013; Vaillant, 2012). Due to the COVID-19 outbreak and its consequences successful completion of these tasks could be frustrated or blocked. Therefore, in the present study we predict that not only the severity of depressive and anxiety symptoms during the COVID-19 pandemic will vary depending on the developmental stage, but also those factors that intensify and maintain these symptoms in different age groups will differ.

The goals of our study are twofold. First, we want to indicate which developmental stage is related to the greatest risk of depressive and anxiety symptoms during the pandemic. Secondly, we want to examine what are the predictors of depressive and generalized anxiety symptoms in different age groups during the COVID-19 lockdown. The current study, to our knowledge, is the first to investigate this topic in individuals in different age groups on representative sample. An improved understanding of the factors related to depressive and anxiety symptoms in various age groups may contribute to earlier identification of emotional 
disorders in high-risk groups during the COVID-19 pandemic. It could also enhance the tailoring and implementation of more effective therapeutic and preventive interventions for individuals with high severity of depressive and anxiety symptoms in order to avoid longterm negative outcomes due to the COVID-19 outbreak.

\section{Developmental and epidemic-related factors associated with depressive and anxiety symptoms in various age groups during the COVID-19 outbreak}

Current sociodemographic trends towards later age to enter into marriage, the parenthood, and longer time of education have led to the rise of a new stage of life at ages 1829 years: emerging adulthood (Arnett et al., 2014). In this developmental phase individuals usually focus on building autonomy, separation (e.g. emotional, financial) from their family, continuing education, and building friendships and romantic relationships. In the established adulthood (Mehta et al., 2020) covering a period between 30 and 44 years of age, people usually start their own family, build a career and try to maintain balance between professional work, their own interests as well as childcare. In the middle adulthood, i.e. between the ages of 45 to 60 , adults usually reach economic and occupational stability, start to care after own parents, and cope with greater autonomy of own children. In the late adulthood, i.e. from about 60 years old people continue to engage in activities in which they maintain high efficiency, focus more on their own health, sum up their life, and share with younger people acquired life experiences (Erikson \& Erikson, 1997; Feldman, 2018; Vaillant, 2012). The COVID-19 pandemic can temporarily disturb or block some of these psychosocial processes, causing frustration, uncertainty and fear, which may lead to an increased emotional distress reflecting in depressive and anxiety symptoms.

Considering the specificity of tasks and needs dominating in different periods of life, mandatory social distancing, isolation from people outside the household, and restrictions on 
movement and travel can be particularly distressing for emerging adults as they may interfere with building their autonomy or establishing and maintaining romantic relationships. Elmer et al. (2020), who have conducted the study among students in Switzerland before and during the COVID-19 found that students' levels of depressive and anxiety symptoms were associated with: more worries about one's family and friends, the future career, isolation in social networks, lack of interactions, and emotional and physical isolation. Research among Chinese students of a medical college (Cao et al. 2020) revealed that the severity of general anxiety symptoms in students was related to lower availability of social support and more worries about academic delays as well as negative effects of pandemic on daily-life and economic situation. Individuals in established and middle adulthood may experience emotional distress as a result of overloading with the need to reconcile family (including allday child care) and professional responsibilities during a pandemic. On the other hand, depressive and anxiety symptoms may be associated with the perceived risk to life and health in individuals who are at risk of COVID-19 complications due to older age (Applegate \& Ouslander, 2020), whereas in young adults this factor may not play a major role in emotional well-being during the COVID-19 pandemic.

\section{Depressive and anxiety symptoms during the COVID-19 pandemic in various age groups}

The majority of existing studies on mental health during the COVID-19 pandemic consistently show that individuals in early adulthood display higher severity of depressive and anxiety symptoms than other age groups (Ahmed et al., 2020; Huang \& Zhao, 2020; Ozamiz-Etxebarria et al., 2020). They also indicate that the younger people are, the more severe symptoms they experience (González-Sanguino et al, 2020; Jia et al., 2020; Traunmüller et al., 2020). However, only in two studies, that were conducted in China, older 
individuals demonstrated higher severity of anxiety and depressive symptoms and other psychopathological symptoms than younger people during COVID-19 outbreak (Qiu et al., 2020; Tian et al. 2020).

A study conducted in the initial stage of the COVID-19 outbreak in northern Spain revealed that individuals in the age range of 18-25 experienced higher levels of stress, anxiety and depression than those in the 26-60 years age group (Ozamiz-Etxebarria et al., 2020). Huang and Zhao (2020) demonstrated that the severity of generalized anxiety disorder and depressive symptoms were significantly higher for participants under 35 years of age than for participants aged 35 or older in China during COVID-19 outbreak. Similarly, research of Ahmed et al. (2020) has revealed that people aged between 21 and 40 years old were in a more vulnerable position regarding their mental health status and alcohol consumption than other age groups in this country. A study conducted in Austria within the first two weeks after implementation of strict personal restrictions has shown that the older the participants the less they reported stress, anxiety, and depressive symptoms (Traunmüller et al., 2020). Jia et al. (2020) demonstrated that younger age was significantly associated with greater levels of anxiety and depressive symptoms, and level of stress in people from the United Kingdom in the first four-six weeks of social distancing. Moreover, research conducted in Spain revealed that age is significantly negatively associated with depressive and anxiety symptoms during COVID-19 outbreak (González-Sanguino et al, 2020). Thus, many studies indicated that the youngest adults experience the highest levels of emotional distress during the COVID-19 pandemic. Little is known, however, about specific factors that are related to anxiety and depressive symptoms at various developmental stages.

\section{Demographic and COVID-19-related risk factors of depressive and anxiety}


Although previous research revealed that young age is one of the key risk factors of depressive and anxiety symptoms in adults during the COVID-19 pandemic, studies demonstrated that also other demographic and COVID-19-related variables are associated with emotional distress. Consistently with research conducted prior to the pandemic (e.g. Grenier et al., 2019; Kuehner, 2003; Salk et al., 2017), several studies indicated that women experienced more depressive and anxiety symptoms during the pandemic than men (e.g. Jung et al., 2020; Kamal \& Othman, 2020; Sigdel et al., 2020; Sønderskov et al., 2020). Moreover, individuals who had lost their income or experienced worsening of their financial situation during the COVID-19 outbreak showed markedly higher levels of emotional distress compared to those with stable financial situation (Cao et al., 2020; Shevlin et al., 2020). Also, poor self-rated health was associated with higher levels of stress, anxiety, and depression during the outbreak (Ozamiz-Etxebarria et al., 2020; Traunmüller et al., 2020; Shevlin et al., 2020; Wang et al., 2020). Greater perceived risk and worries about contracting COVID-19 and comorbid health complications were related to higher emotional distress in some studies (Jia et al., 2020; Shevlin et al., 2020; Wang et al., 2020). More severe levels of depressive and anxiety symptoms were also found in those who were students (Mazza et al., 2020; Traunmüller et al., 2020; Wang et al., 2020) or were unemployed (Kamal \& Othman, 2020; Mazza et al., 2020). Lower level of education has been shown to be a risk factor for depressive and anxiety symptoms in several studies (Gao et al., 2020; Mazza et al., 2020; Tian et al., 2020; Traunmüller et al., 2020). However, a few studies indicated the opposite: higher level of education was related to greater emotional distress (Kamal \& Othman, 2020; Moghanibashi-Mansourieh, 2020). Finally, social support was associated with lower levels of anxiety and/or depressive symptoms during the COVID-19 epidemic (Cao et al. 2020; Elmer et al., 2020; González-Sanguino et al., 2020; Ni et al., 2020). 


\section{Current study}

There were a few aims of the current study. The first one was to investigate the differences in levels of depressive and anxiety symptoms in various age groups in Polish poulation: emerging adulthood (18-29 years), established adulthood (30-44 years), middle adulthood (45-59 years), and late adulthood (60-85 years). The second one was to study the differences in various age groups in the perceived severity of various difficulties related to the COVID-19 pandemic such as: limited contact with other people and friends, various restrictions of movement and freedom outside of home, problems in interpersonal relationships with relatives at home during the lockdown, being overloaded with duties, and a sense of unpredictability and anxiety related to the spread of the virus. The third goal was to investigate which of these difficulties are the most strongly related to generalized anxiety and depressive symptoms during the pandemic in various age groups. Additionally, we investigated and controlled other sociodemographic and COVID-19-related factors that were found to be related to anxiety and depressive symptoms during the COVID-19 outbreak such as: gender, educational level, student status, unemployment, worsening of the financial situation during the COVID-19 pandemic, self-rated health status, perceived threats to health and life, as well as social support during the COVID-19 outbreak.

As the situation with the COVID-19 pandemic is new and to some extent unpredictable, our study was partly exploratory in nature. However, after reviewing studies conducted during the pandemic and drawing on the theoretical considerations concerning tasks and needs associated with specific developmental stages, we have put forward the following hypotheses:

H1. Depressive and generalized anxiety symptoms would be the highest in adults between 18-29 years in comparison to other age groups during the COVID-19 pandemic. 
H2. Limited contact with other people and friends, various restrictions to movement and freedom outside of home, and difficulties in interpersonal relationships with relatives at home during lockdown would be the most difficult for adults between 18- 29 years.

H3. The perceived COVID-19-related risk to health and life would be higher for adults over 60 years of age than for adults between 18-29 years.

H4. Generalized anxiety and depressive symptoms during the COVID-19 outbreak would be related to limited contact with other people and friends, various restrictions to movement and freedom outside of home, difficulties in interpersonal relationship with relatives at home during lockdown for adults between 18-29 years.

H5. Generalized anxiety and depressive symptoms will be related to the perceived COVID19-related risk to health and life for adults over 60 years of age.

\section{Situation in Poland during data collection}

The study was conducted between 4th and 8th of May, 2020. At that time, two months had passed since the detection of the first case of coronavirus infection in Poland and six weeks since the beginning of the lockdown. The number of people infected with coronavirus exceeded 14.000, the number of fatalities approached 700, about 4000 people recovered. The media were stressing information on the insufficient number of tests to detect the presence of coronavirus (especially among physicians) and experts' opinions that the number of infected may be between 40000 and 50000. Although for about two weeks all Poles had been obligated to wear masks, the most restrictive recommendations that locked people down in their homes had already been loosened: the ban on recreation in forests and parks was removed, the number of people in shops has increased. 


\section{Method}

\section{Participants}

A total of 1179 adults took part in the study. The group was a representative sample of the Polish population in terms of sex, age, and place of residence. In order to ensure the quality of the data, 64 outliers were removed: 27 participants using only the highest or lowest scale levels in the whole survey, 25 participants using only the midpoint of the scale, 12 participants who had psychological scales' scores below or above 3SD. Finally, data from 1115 participants were analyzed. Vast majority $(99 \%, \mathrm{n}=1108)$ of participants declared that Poland was their country of origin. The sample included 563 females $(50.5 \%)$ and 552 males $(49.5 \%)$, in the age range from 18 to $85(M=44.64, S D=15.84)$. Over one third $(37 \%)$ of participants lived in a village, $12.1 \%$ lived in a small town (up to 20000 residents), $21.3 \%$ lived in a medium town (20000-99000 residents), 17.4\% lived in a big town (100000-500000 residents), and $11.7 \%$ lived in a big city (over 500000 residents). Detailed demographic characteristics of the four age groups (18-29, 30-44, 45-59, 60-85 years) and analysis of differences between them are presented in Table 1 .

\section{Measures}

The Patient Health Questionnaire-9 (PHQ-9; Kroenke et al., 2001) is a screening tool for assessing the risk of depressive disorders. It consists of nine basic items and one additional item. The main items refer to the frequency of depressive symptoms (described in the DSMIV diagnostic criteria) in the last two weeks. The participants give answers on a scale from 0 not at all to 3 - nearly every day. An additional item, which is not included in the overall result, refers to the extent to which the symptoms interfered with the participants' functioning. The questionnaire has good psychometric properties (e.g. Kroenke et al., 2001; 
Levis et al., 2019). We used the Polish translation of PHQ-9 developed by the MAPI Research Institute (www.phqscreeners.com). The Cronbach's alpha was $\alpha=.91$ in our study.

The Generalized Anxiety Disorder-7 (GAD-7; Spitzer et al., 2006) is a screening measure for assessing the risk of generalized anxiety disorder. It consists of seven items about the frequency of symptoms during the last two weeks. The participants answer on a scale from 0 - not at all to 3 - nearly every day. The questionnaire has good psychometric properties (e.g. Rutter \& Brown, 2017; Spitzer et al., 2006). In our study, we used the GAD-7 version translated into Polish by the MAPI Research Institute (www.phqscreeners.com). The Cronbach's alpha was $\alpha=.94$ in our study.

Scale of Perceived Health and Life Risk of COVID-19. Participants were asked six questions about the subjective risk of: (i) COVID-19 infection; (ii) serious adverse health effects and complications due to a coronavirus infection; and (iii) life-threat as a result of the infection. Each of the three risk areas were assessed using two items: one item relates to oneself and one to one's beloved ones. Six items were rated on a five-point scale from 1 - very low to 5 very high. The higher the score (from 6 to 30), the higher the perceived health and life risk of COVID-19. Cronbach's alpha was $\alpha=.92$.

Scale of Epidemic-Related Difficulties. Participants were asked sixteen questions about possible difficulties during the pandemic. They were asked to indicate to what extent each of the following is currently a problem for them and answered on a scale from 1 - it is not a problem at all to 4 - it is definitely a problem for me. Based on an exploratory factor analysis (for details and wording of all items see Supplementary Material), we created four subscales: relationships and difficulties at home that covers being overloaded by everyday duties, feeling of loneliness, problematic home relationships and a need for privacy (4 items, $\alpha=.76$ ), lack of social contacts ( 2 items, $\alpha=.82$ ), external restrictions referring to obligations 
imposed to stop the spread of the virus ( 3 items, $\alpha=.66$ ), and fear and uncertainty related to pandemic course and the incidence of Covid-19 (2 items, $\alpha=.68)$.

Social Support Scale. Participants were asked five questions about the social support obtained during the pandemic. We asked about three kinds of social support, basing our items on the brief version of the Medical Outcomes Study Social Support Survey (Holden et al., 2014): emotional-informational support, tangible support, and positive social interaction and affectionate support. Participants answered to what extent they obtain a particular form of support on a scale from 1 definitely not to 5 definitely yes. Cronbach's alpha was $\alpha=.78$.

Health problems. Participants were asked whether they suffered from any pre-existing medical conditions (chronic diseases, immunosuppressive therapy, etc.) that may put them at risk of severe COVID-19 infection. They answered on a nominal scale (1 - yes, 2 - don't know, and 3 - no). This variable was dummy-coded for the regression analysis with "no" answer as a reference value.

Income continuity. Participants were asked whether they had an income continuity during the COVID-19 pandemic (scale: 0 - no, 1 - yes)

Financial situation. Participants were asked whether their financial situation had changed due to the COVID-19 pandemic and answered on a scale from -3 - has definitively worsened to 3 - has definitely improved. The variable was recoded for the regression analysis to a scale from 1 to 7 .

\section{Procedure}

This study was approved by the institutional review board of Department of Psychology, University of Warsaw. Participants were recruited online from the Polish research panel ARIADNA. Participation was anonymous, and participants were rewarded 
with points which they could exchange for small gifts. The presented findings are part of a larger research project on psychological aspects of the COVID-19 pandemic in the Polish population.

\section{Data analytic strategy}

In order to present detailed sociodemographic characteristics of age groups we computed descriptive statistics and assessed the differences between age groups in sociodemographic variables, the $\chi^{2}$ test was used. Effect size for $\chi^{2}$ test was calculated using Cramér's V (Cramér, 1961). Additionally, for pairwise comparisons, the $\chi^{2}$ test with Bonferroni's adjustment for multiple comparisons (Armstrong, 2014) was used. Taking into account that income continuity had 391 missing data, the analysis of differences for this variable was carried out on a sample of 724 participants. Additionally, in order to assess the differences between age groups in financial situation, the Kruskal-Wallis test with Dunn's multiple comparison post-hoc testing (Dunn, 1964; Kruskal \& Wallis, 1952) was applied. The magnitude of differences was assessed by $\eta_{\mathrm{H}}^{2}$ effect size (Cohen, 2008). Also, descriptive statistics such as means $(M)$, standard deviations $(S D)$, median $(M e)$ and quartile deviation $(Q)$ were calculated.

To analyze the differences between age groups in anxiety and depressive symptoms, one-way ANOVAs were used. The Tukey multiple comparison post-hoc tests were implemented for anxiety symptoms. However, taking into account the violation of variance homogeneity assumption in the depressive symptoms measure, for depressive symptoms the Dunnett T3 (Dunnett, 1980) multiple comparison post-hoc tests were carried out. Analogically, one-way ANOVAs were used in the analysis of age groups differences in social support and perceived health and life risk of COVID-19. Taking into account that the assumptions of variance homogeneity were achieved, the Tukey post hoc test was implemented. 
In order to assess the differences between age groups on the scale of epidemic-related difficulties, the Kruskal-Wallis test with Dunn's multiple comparison post-hoc testing (Dunn, 1964; Kruskal \& Wallis, 1952) was applied. Additionally, descriptive statistics such as means $(M)$, standard deviations $(S D)$, median $(M e)$ and quartile deviation $(Q)$ are presented for all groups. The magnitude of differences was assessed by $\eta_{\mathrm{H}}^{2}$ effect size (Cohen, 2008). Additionally, in order to verify whether there is a difference between the respective age groups in the epidemic-related difficulties, the Jonckheere-Terpstra test for ordered alternatives was used (Jonckheere, 1954; Terpstra, 1952). More precisely, the JonckheereTerpstra test was to be used to determine if there is a statistically significant trend between age groups and epidemic-related difficulties.

We used single linear regressions to calculate the univariate associations between independent and dependent variables and multiple regressions to determine the multivariate effects of COVID-19-related factors on depressive and anxiety symptoms among studied age groups.

\section{Results}

Sociodemographic description of the age groups

Significant differences were found between age groups in education level, financial situation during the COVID-19 pandemic, health problems, being unemployed, financial situation and in income continuity (see Table 1). However, effect sizes of these differences varied from small to moderate (see Cohen, 1988; Cohen, 2008).

Table 1. Sociodemographic characteristic of the four age groups. [Insert Table 1 here] 
We conducted one-way ANOVA to test differences in anxiety and depressive symptoms between the four age-groups. The results revealed a significant univariate effect on both variables (see Table 2). The youngest individuals (aged 18-29) displayed significantly higher levels of anxiety than those in the 45-59 and 60-85 age groups ( $p$ s $<.001)$. Individuals in the age range of 30-44 demonstrated higher level of anxiety than individuals aged 60 and older ( $p=.02$; see Table 2$)$. The youngest group of individuals displayed also a significantly higher level of depressive symptoms than the three other groups $(p<.001)$. Participants aged 30-44 experienced a higher level of depression symptoms than the oldest group of individuals $(p=.007 ;$ Table 2$)$.

Table 2. Differences in depressive and anxiety symptoms across the four age groups

[Insert Table 2 here]

Social support and perceived health and life risk of COVID-19 among age groups

There was an age difference in perceived health and life risk of COVID-19, $\mathrm{F}_{(3,1111)}=$ $27.15, p<.001, \eta_{\mathrm{p}}{ }^{2}=.07$. More specifically, the results showed that the individuals in the 18 29 age group $(M=2.74, S D=.84)$ demonstrated lower level of perceived health and life risk of COVID-19 than the individuals in the 30-44 age group $(M=3.00, S D=.86, p=.001)$, the 45-59 age group $(M=3.25, S D=.84, p<.001)$ and the $60-85$ age group $(M=3.35, S D=.84$, $p<.001)$. Additionally, people in the $30-44$ age group $(M=3.00, S D=.86)$ presented lower level of perceived health and life risk of COVID-19 than the individuals in the 45-59 age group $(M=3.25, S D=.84, p=.002)$ and in the 60-85 age group $(M=3.35, S D=.84, p<$. 001). There were no age groups differences in social support, $\mathrm{F}_{(3,111)}=1.92, p=.13$. 
There was a difference between the respective age groups in epidemic-related difficulties associated with relationships and difficulties at home (see Table 3). More specifically, based on the Jonckheere-Terpstra test, it can be indicated that the older the age group was, the lower was the level of epidemic-related difficulties associated with relationships and difficulties at home. Additionally, there was a trend between the respective age groups in epidemic-related difficulties associated with fear and uncertainty related to the spread of the virus. More specifically, based on the Jonckheere-Terpstra test, the results showed that the older the age group was, the higher the level of epidemic-related difficulties associated with fear and uncertainty related to the spread of the virus. Additionally, we found a trend between the respective age groups in boredom and monotony, and a trend between the respective age groups in feeling lost in the recommendations and restrictions. More specifically, the older the age group was, the lower was the level of these epidemic-related difficulties. Moreover, the results showed age group differences, without a trend, in epidemicrelated difficulties associated with lack of social contacts.

Table 3. Differences in the epidemic-related difficulties across the four age groups.

[Insert Table 3 here]

\section{Predictors of anxiety and depressive symptoms among groups}

We conducted a series of univariate regressions to investigate which factors (demographic variables and psychological factors: social support, perceived health and life risk of COVID-19, as well as epidemic-related difficulties) were related to depressive and anxiety symptoms in various age groups. In terms of demographic characteristics, we found the age-related differences in the association between anxiety and depressive symptoms and sex, education level, income continuity, financial situation, and health problems (Table 4). Difficulties at home and in relationships, perceived health and life risk of COVID-19, fear 
and uncertainty as well as necessity to deal with external restrictions were important predictors of depressive and anxiety symptoms in all the age groups. Lack of social contacts was a significant predictor of higher level of depressive and anxiety symptoms among the youngest (18-29) and the oldest (60-85) participants (Table 5).

Table 4. Univariate effects of demographic variables on anxiety and depressive symptoms [Insert Table 4 here]

Table 5. Univariate effects of epidemic-related variables on anxiety and depressive symptoms [Insert Table 5 here]

We also conducted a multivariate regression analysis to examine effects of epidemicrelated difficulties in predicting depressive and anxiety symptoms. Difficulties experienced in relationships and at home appeared to be a significant predictor of both anxiety and depressive symptoms in all four groups. Fear and uncertainty related to epidemic remained a significant predictor of anxiety in all age groups except the youngest one (18-29 years), and of depressive symptoms among individuals aged 45-59 and 60-85. Perceived health and life risk of COVID-19 was a significant predictor of anxiety symptoms only among individuals aged 30-59 and of depression among participants aged 30-44.

Table 6. Epidemic-related variables regressed on anxiety and depressive symptoms in the four age groups

[Insert Table 6 here] 


\section{Discussion}

Our study is the first to investigate various factors and epidemic-related difficulties associated with depressive and anxiety symptoms in different age groups during the COVID19 outbreak. Consistent with our first hypothesis, the emerging adults (age 18-29) experienced more depressive symptoms than all the other age groups. Emerging adults showed also more generalized anxiety than the two oldest age groups (45-59 and 60-85 years). Moreover, established adults (30-44 years) experienced more depressive and anxiety symptoms than the oldest group (60-85 years). Our findings on a representative sample of the Polish population are in line with previous studies conducted in various parts of the world showing that the emerging and young adults experience the highest levels of various forms of emotional distress during the COVID-19 pandemic (Ahmed et al., 2020; Huang \& Zhao, 2020; Ozamiz-Etxebarria et al., 2020). It is also in line with previous findings that age is negatively correlated with anxiety and depressive symptoms during the pandemic (GonzálezSanguino et al, 2020; Jia et al., 2020; Traunmüller et al., 2020). Although, two previous studies conducted in China (Qiu et al., 2020; Tian, et al. 2020) indicated that the oldest group also is characterized by high levels of emotional distress, our study shows that the oldest adults experience the lowest levels of anxiety and depressive symptoms. These findings are in contrast to studies conducted prior to the COVID-19 pandemic showing that women over 50 years of age in Poland (Polish National Health Fund, 2020), and people in the age range of 55-74 worldwide (World Health Organization, 2017) manifest the highest risk of depressive symptoms. Our findings point out that it is important to better understand mechanisms underlying the emotional distress during the COVID-19 pandemic in various developmental periods. It is crucial to explore how various age groups differ in the perceived severity of the difficulties related to the pandemic, as well as how these difficulties are related to depressive and anxiety symptoms. 
Our results show that adults in the age range of 18-29 years and 30-44 years experience the highest levels of difficulties in relationships and at home that refer to being overloaded by everyday duties, feeling of loneliness, problematic home relationships and unmet need for privacy during the COVID-19 epidemic. Moreover, only the emerging adults reported higher levels of loneliness and feeling of being abandoned, as well as boredom and monotony as compared to the two oldest groups. Also, the youngest group experienced higher levels of perceived difficulties with lack of contacts with beloved ones and friends than adults in the age range of 30-44 years. These results can be understood in light of the theories describing developmental challenges and needs characteristic for the different periods of life (Erikson \& Erikson, 1997; Feldman, 2018; Vaillant, 2012). We suppose that the emerging adults' important developmental tasks and needs, in particular building autonomy, separation from the family of origin, building friendships and romantic relationships, were blocked and frustrated during the lockdown. Thus, staying at home with the family could be difficult for emerging adults, especially when they were experiencing problems in relationships with household members prior to the pandemic. When emerging adults were forced to stay at home and limit their external contacts with friends and other people, these relational problems could escalate. Thus, they could experience loneliness and isolation (being apart from peers, sometimes even romantic partners) while at the same time experiencing lack of privacy and negative relations among household members ( $\mathrm{Bu}$ et al., 2020).

Some of the individuals in the period of the established adulthood in the age range of 30-44, who also experienced the highest levels of difficulties in relationships and at home, could on the other hand feel overwhelmed with combining their professional work with private life including taking care of the children. Thus, the important developmental task of building balance between professional work, their own interests, as well as childcare could be 
to some extent disturbed by the COVID-19 pandemic and led to difficulties with lack of privacy, being overloaded with daily duties, and it provoked quarrels and tensions at home (Cluver et al., 2020). In Poland grandparents or other relatives often help in taking care of the children, what in the lockdown times was very limited and possibly deepened the feeling of being overwhelmed with daily duties and being alone in the face of the challenges of a daily life. Adults in the age groups of 45-59 and 60-85 years could perceive difficulties at home as less severe because their daily life, home relationships and occupational situation are usually more stable and their children are more independent or have their own families.

The oldest group experienced higher levels of difficulties with lack of social contacts, in particular with beloved ones and friends, than adults in the age range of 30-44 and 45-59 years, but did not differ in this domain from the emerging adults. Many of the individuals in the late adulthood during the COVID-19 pandemic almost totally avoided social contacts with other people, even with own family, children and grandchildren, because of a risk of serious health complications and life-threat due to SARS-Cov-2 infection (Wu, 2020). Older adults have also less experience with new technologies as compared to other age groups. During the pandemic new channels of communication enabled people to maintain their relationships in a virtual form. For older people access to new technologies could have been also restricted due to age-related health problems (e.g., poor eyesight, problems with motor coordination). Keeping relationships with others, especially friends in a similar age, could have been particularly difficult for the oldest group. Finally, the oldest age group experienced also the highest levels of uncertainty and fear related to the epidemic and the spread of the virus - probably because of the threat to health and life of oneself, as well as of friends and beloved ones. We may assume that for this group the situation of the COVID-19 pandemic and its negative consequences could be also more real due to their own experiences of smallpox epidemic in Poland in 1963 or other serious infectious diseases like polio, measles 
(currently limited by vaccinations) and their parents' or relatives' experiences of the Spanish flu epidemic in 1918.

Contrary to our hypothesis, various groups did not differ significantly in the level of difficulties associated with external restrictions due to the COVID-19 pandemic. Official regulations affected daily functioning of all adults despite of age and limited their feeling of liberty in public life. We can assume that wearing face masks was uncomfortable for everyone and all adults had to adapt to new ways of shopping. Therefore, adults in all age groups could similarly experience these restrictions and no group differences were revealed.

Finally, we investigated which factors (demographic factors, social support, perceived health and life risk of COVID-19 and epidemic-related difficulties) were the most strongly related to levels of depressive and anxiety symptoms in various age groups. In our multivariate regression model, epidemic-related variables explained from $21 \%$ (in established adulthood) to $24 \%$ (in emerging adulthood) of variance of depressive symptoms, as well as from $21 \%$ (in the youngest group) to $31 \%$ (in the oldest group) variance of anxiety symptoms. In the youngest age group (18-29 years) anxiety and depressive symptoms were related the most strongly, similarly as in the other age groups, to difficulties at home and in relationships. As was mentioned previously, the frustration of the developmental needs (spending time outside from home, separation from one's family, building friendships and romantic relationships) of this age group could lead to depressive and anxiety symptoms. Additionally, difficulties associated with external restrictions due to the pandemic were a significant predictor of anxiety and depressive symptoms even when accounted for the shared variance with other epidemic-related difficulties only in this age group. Such restrictions could interfere with the need to build autonomy and independence in emerging adults and therefore lead to emotional distress. 
Social support during the epidemic, fear and uncertainty related to pandemic, as well as perceived health and life risk of COVID-19 were not significant predictors of depressive and anxiety symptoms when accounting for the shared variance with other epidemic-related difficulties in the youngest age group. It confirms our hypothesis that difficulties related to various restrictions and lockdown are more strongly related to the depressive and anxiety symptoms in emerging adults than perceived health and life risk of COVID-19, anxiety and uncertainty concerning the spread of the virus. Since emerging adults do not perceive high levels of health and life risk of COVID-19, they may also not need that much social support during the COVID-19 epidemic, because they are not dependent on the help of others in satisfying their basic needs (e.g., by shopping in stores and pharmacies).

Finally, lack of income continuity was related to anxiety and depressive symptoms only in the youngest age group in addition to worsening of financial situation during the COVID-19 pandemic, which was associated with emotional distress in almost all the age groups. Additionally, the percentage of individuals who experienced lack of income continuity (40\%) was the largest in the youngest adults. Many students and emerging adults have an unstable work situation, working upon civil-law-contracts in workplaces that were particularly affected during the pandemic (tourism, gastronomy). It could have led to difficulties to meet their basic needs. As some of the emerging adults had to return to the family home during the COVID-19 outbreak, their financial dependence on their parents increased, which could have been experienced in terms of developmental stagnation or even regression. Young adults may be more at risk of negative changes and expectations for their future (passing exams, continuing studies, stability of work and income) and research shows that people who are able to imagine themselves positively in the future experience less difficulties with dealing with crises and sustaining positive emotions (Markus \& Nurius, 1986; Sheldon \& Lyubomirsky, 2006). 
Difficulties at home and in relationships were one of the most important predictors of depressive and anxiety symptoms in all the age groups: 18-29, 30-44, 45-59 and 60-85 years. Having difficult relationships with members of household, lack of privacy, being overwhelmed with daily duties all contribute to the experienced depressive and anxiety symptoms during the COVID-19 lockdown. However, in all three older age groups (30-44, 45-59 and 60-85 years) but not in the youngest group also health-related problems and fear and uncertainty related to the spread of the virus were associated with higher levels of depressive and/or generalized anxiety symptoms. Additionally, in the groups in the age range of 30-44 and 45-59 perceived health and life risk of COVID-19 was related to emotional distress. Thus, emotional functioning of the older age groups seems to be affected by the health-related concerns and fears (perhaps related to their own health, but also health of the beloved ones) to a higher extent than in the youngest age group. This may be the reason why epidemic-related variables explained the largest part of the variance of anxiety symptoms (such as worry, tension, and fear that something bad would happen) in the oldest age group, as compared to the younger age groups.

Surprisingly, difficulties related to the lack of social contacts were negatively associated with depressive and/or anxiety symptoms in the adults in the age range of 30-44, as well as 45-59 years when accounted for the shared variance with other epidemic-related difficulties. However, they were not significant predictors of depressive symptoms in univariate regression, in both these age groups, and were a positive predictor of anxiety symptoms in the 30-44 age group in univariate regression. Many people in these age groups were overwhelmed by combining roles and responsibilities at home (being a partner, a parent and an employee), experienced depressive and anxiety symptoms, and might not even have time to reflect on social relations with other people and their own need of contact with others. 
Moreover, social support was a negative predictor of depressive and anxiety symptoms only in adults in the age range of 30-44 years when accounted for the shared variance with other epidemic-related difficulties. Since many adults in this age group are working and have younger children at home and may be overwhelmed with many duties, social support may be particularly important for them and may provide them with a sense of security and balance between work and family responsibilities, reducing emotional distress.

Additionally, in emerging adults vocational education was associated with lower levels of depressive symptoms than a university degree, whereas secondary education was related to higher levels of depressive symptoms than a university degree. Primary education was associated with higher levels of anxiety symptoms than university degree in the adults in the $30-44$ years age range. It could be that vocational education in the emerging adults is associated with the most stable job situation (having a profession), whereas secondary education in emerging adults and primary education in older adults (30-44 years of age) may be related to lower levels of stabilization resulting in emotional distress.

Finally, women experienced higher levels of depressive symptoms than men in the youngest age group as well as in the oldest age group. Various previous studies indicated that women are at a higher risk for depression and anxiety disorders than man not only during the pandemic (Jung et al., 2020; Kamal \& Othman, 2020; Özdin \& Özdin, 2020; Sigdel et al., 2020; Sønderskov et al., 2020), but also in general (e.g. Kuehner, 2003; Salk et al., 2017). However, surprisingly men experienced higher levels of generalized anxiety in the oldest adults group (60-85 years). Higher risk of serious health complications and death related to COVID-19 in men than women could contribute to higher levels of anxiety in older men than in women (Jin et al., 2020).

\section{Limitations}


There are several limitations of the current study. The study included only individuals who were users of internet and were members of the online panel. Thus, it limits generalization of our findings to the other populations, especially in the case of the oldest age group. In addition, because our study was cross-sectional, we can conclude about the strength and direction of relationships between measured constructs, but the possibility of inferring about temporal and causal relations between variables is limited. Finally, the depressive and anxiety symptoms were measured only with self-report scales that are subjective and vulnerable to biases such as social desirability, the participant's mood or the need for selfenhancement (Podsakoff et al., 2003; Wojcik et al., 2015).

\section{Future Directions}

Our study gives an insight to the predictors of depressive and anxiety symptoms in various age groups during the COVID-19 pandemic. As this study was cross-sectional, it would be important to conduct also a longitudinal study on the relationships between factors and difficulties related to the pandemic, and depressive and anxiety symptoms in various age groups, as well as to test cross-lag models. It should be investigated how severity of depressive and anxiety symptoms in different age groups change over time during and after the pandemic. It would be also valuable to explore which of the psychological protective mechanisms triggered by the changes and difficulties related to the COVID-19 pandemic are particularly important in a given age group.

It is also worth considering that although most of the studies suggest that young adults experience more severe emotional distress during the COVID-19 pandemic than the older ones, there is some evidence that in the Chinese society this regularity may be different (Qiu et al., 2020; Tian et al. 2020). Kowal et al. (2020, preprint) suggests that in the collectivistic cultures people are more distressed by the pandemic. Thus, it would be interesting to check whether the culture may be a moderator between age and distress during the pandemic. 


\section{Conclusions and Implications}

Our results have important clinical implications. The different predictors of anxiety and depressive symptoms in the different age groups suggest that the psychological support during the pandemic should be age-specific, considering potentially compromised specific developmental tasks during the COVID-19 outbreak. Our study also indicates the need for intensive preventive and therapeutic interventions addressed to at-risk individuals (among others adults in emerging and early adulthood, and those experiencing difficult relations at home), aimed at reducing the risk of developing depressive and anxiety symptoms during the COVID-19 pandemic and preventing negative long-term outcomes.

\section{References}

Ahmed, M., Ahmed, O., Aibao, Z., Hanbin, S., Siyu, L., \& Ahmad, A. (2020). Epidemic of COVID-19 in China and associated psychological problems. Asian Journal Of Psychiatry, 51, 102092. https://doi: 10.1016/j.ajp.2020.102092

Asmundson, G. J., \& Taylor, S. (2020). How health anxiety influences responses to viral outbreaks like COVID-19: What all decision-makers, health authorities, and health care professionals need to know. Journal of Anxiety Disorders, 71, https://doi: 102211. 10.1016/j.janxdis.2020.102211

Anderson, R. M., Heesterbeek, H., Klinkenberg, D., \& Hollingsworth, T. D. (2020). How will country-based mitigation measures influence the course of the COVID-19 epidemic?. The Lancet, 395(10228), 931-934. https://doi.org/10.1016/S0140-6736(20)30567-5

Applegate, W. B., \& Ouslander, J. G. (2020). COVID-19 presents high risk to older persons. Journal of the American Geriatrics Society, 68(4), 681. https://doi.org/10.1111/jgs.16426 
Armstrong, R. A. (2014). When to use the Bonferroni correction. Ophthalmic and Physiological Optics, 34(5), 502-508. https://doi.org/10.1111/opo.12131

Arnett, J. J., Žukauskienè, R., \& Sugimura, K. (2014). The new life stage of emerging adulthood at ages 18-29 years: Implications for mental health. The Lancet Psychiatry, 1(7), 569-576. https://doi.org/10.1016/S2215-0366(14)00080-7

Bu, F., Steptoe, A., \& Fancourt, D. (2020). Who is lonely in lockdown? Cross-cohort analyses of predictors of loneliness before and during the COVID-19 pandemic. medRxiv. https://doi.org/10.1101/2020.05.14.20101360

Cao, W., Fanga, Z., Houc, G., Hana, M., Xua, X., Donga, J., \& Zhen J., (2020) The psychological impact of the COVID-19 epidemic on college students in China. Psychiatry Research. https://doi.org/10.1016/j.psychres.2020.112934

Cluver, L., Lachman, J. M., Sherr, L., Wessels, I., Krug, E., Rakotomalala, S., ... \& Butchart, A. (2020). Parenting in a time of COVID-19. The Lancet, 395(10231), E64. https://doi.org/10.1016/S0140-6736(20)30736-4

Cohen, B. H. (2008). Explaining psychological statistics (3rd ed.). John Wiley \& Sons.

Cohen, J. (1988). Statistical power analysis for the behavioral sciences (2nd ed.). Erlbaum Cramér, H. (1961). Mathematical methods of statistics. Princeton University Press.

Duan, L., \& Zhu, G. (2020). Psychological interventions for people affected by the COVID19 epidemic. The Lancet Psychiatry, 7(4), 300-302. https://doi.org/10.1016/S22150366(20)30073-0

Dunn, O. J. (1964). Multiple comparisons using rank sums. Technometrics, 6(3), 241-252. https://doi.org/10.2307/1266041

Dunnett, C. W. (1980). Pairwise multiple comparisons in the unequal variance case. Journal of the American Statistical Association, 75(372), 796-800. 
Elmer, T., Mepham, K., \& Stadtfeld, Ch. (2020). Students under lockdown: Assessing change in students' social networks and mental health during the COVID-19 crisis. https://doi.org/10.31234/osf.io/ua6tq

Erikson, E. H., \& Erikson, J. M. (1997). The life cycle completed: Extended version. W. W. Norton.

Feldman, R. S. (2018). Development across the life span (8th ed.). Pearson.

Gao, J., Zheng, P., Jia, Y., Chen, H., Mao, Y., \& Chen, S. et al. (2020). Mental health problems and social media exposure during COVID-19 outbreak. PLOS ONE, 15(4), e0231924. https://doi.org/10.1371/journal.pone.0231924

González-Sanguino, C., Ausín, B., Castellanos, M., Saiz, J., López-Gómez, A., Ugidos, C., \& Muñoz, M. (2020). Mental health consequences during the initial stage of the 2020 Coronavirus pandemic (COVID-19) in Spain. Brain, Behavior, And Immunity. https://doi.org/10.1016/j.bbi.2020.05.040

Grenier, S., Payette, M-C., Gunther, B., Askari, S., Desjardins, F., Raymond, B., \& Berbiche, D. (2019) Association of age and gender with anxiety disorders in older adults: A systematic review and meta-analysis. International Journal of Geriatric Psychiatry, 34(3), 397-407. https://doi.org/10.1002/gps.5035

Holden, L., Lee, C., Hockey, R., Ware, R. S., \& Dobson, A. J. (2014). Validation of the MOS Social Support Survey 6-item (MOS-SSS-6) measure with two large population-based samples of Australian women. Quality of Life Research, 23(10), 2849-2853. https://doi.org/10.1007/s11136-014-0741-5

Huang, Y., \& Zhao, N. (2020). Generalized anxiety disorder, depressive symptoms and sleep quality during COVID-19 outbreak in China: a web-based cross-sectional survey. Psychiatry Research. https://doi.org/10.1016/j.psychres.2020.112954 
Jia, R., Ayling, K., Chalder, T., Massey, A., Broadbent, E., Coupland, C., \& Vedhara, K. (2020). Mental health in the UK during the COVID-19 pandemic: Early observations. https://doi.org/10.1101/2020.05.14.20102012

Jin, J. M., Bai, P., He, W., Wu, F., Liu, X. F., Han, D. M., Liu, S., \& Yang, J. K. (2020). Gender differences in patients with COVID-19: Focus on severity and mortality. Frontiers in Public Health, 8. https://doi.org/10.3389/fpubh.2020.00152

Jonckheere, A. R. (1954). A distribution-free k-sample test against ordered alternatives. Biometrika, 4l(1/2), 133-145. https://doi.org/10.2307/2333011

Kamal, N., \& Othman, N. (2020). Depression, anxiety, and stress in the time of COVID-19 pandemic in Kurdistan Region, Iraq. Kurdistan Journal Of Applied Research, 37-44. https://doi.org/10.24017/covid.5

Kowal, M., Coll-Martín, T., Ikizer, G., Rasmussen, J., Eichel, K., Studzińska, A., Koszałkowska, K., Karwowski, M., Najmussaqib, A., Pankowski, D., Lieberoth, A., \& Ahmed, O. (2020). Who is the most stressed during COVID-19 isolation? Data from 27 countries. https://doi.org/10.31234/osf.io/qv5t7

Kruskal, W. H., \& Wallis, W. A. (1952). Use of ranks in one-criterion variance analysis. Journal of the American statistical Association, 47(260), 583-621. https://doi.org/10.2307/2280779

Kuehner, C. (2003). Gender differences in unipolar depression: an update of epidemiological findings and possible explanations. Acta Psychiatrica Scandinavica, 108(3), 163-174. https://doi.org/10.1034/j.1600-0447.2003.00204.x

Jung, S., Kneer, J., \& Krueger, T. (2020). The German COVID-19 survey on mental health: Primary results. https://doi.org/10.1101/2020.05.06.20090340

Levis, B., Benedetti, A., Thombs, B. D., \& DEPRESsion Screening Data (DEPRESSD) Collaboration. (2019). Accuracy of Patient Health Questionnaire-9 (PHQ-9) for 
screening to detect major depression: Individual participant data meta-analysis. $B M J$ : British Medical Journal, 365, Article 11476.

Markus, H., \& Nurius, P. (1986). Possible selves. American Psychologist, 41, 954-969.

Mazza, C., Ricci, E., Biondi, S., Colasanti, M., Ferracuti, S., Napoli, C., \& Roma, P. (2020). A Nationwide Survey of Psychological Distress among Italian People during the COVID-19 Pandemic: Immediate Psychological Responses and Associated Factors. International Journal Of Environmental Research And Public Health, 17(9), 3165. https://doi.org/10.3390/ijerph17093165

Mehta, C. M., Arnett, J. J., Palmer, C. G., \& Nelson, L. J. (2020). Established adulthood: A new conception of ages 30 to 45. American Psychologist, 75(4), 431-444. https://doi.org/10.1037/amp0000600

Moghanibashi-Mansourieh, A. (2020). Assessing the anxiety level of Iranian general population during COVID-19 outbreak. Asian Journal Of Psychiatry, 51, 102076. https://doi.org/10.1016/j.ajp.2020.102076

Ni, M., Yang, L., Leung, C., Li, N., Yao, X., Wang, Y., Leung, G., Cowling, B., \& Liao, Q. (2020). Mental health, risk factors, and social media use during the COVID-19 epidemic and cordon sanitaire among the community and health professionals in Wuhan, China: Cross-sectional survey. JMIR Mental Health 2020;7(5):e19009 https://doi.org/10.2196/19009

Ozamiz-Etxebarria, N., Dosil-Santamaria, M., Picaza-Gorrochategui, M., \& IdoiagaMondragon, N. (2020). Stress, anxiety, and depression levels in the initial stage of the COVID-19 outbreak in a population sample in the northern Spain. Cadernos de Saúde Pública, 36, e00054020. https://doi.org/10.1590/0102-311X00054020

Özdin, S., \& Bayrak Özdin, Ş. (2020). Levels and predictors of anxiety, depression and health anxiety during COVID-19 pandemic in Turkish society: The importance of gender. 
International Journal of Social Psychiatry, 0020764020927051.

https://doi.org/10.1177/0020764020927051

Qiu, J., Shen, B., Zhao, M., Wang, Z., Xie, B., \& Xu, Y. (2020). A nationwide survey of psychological distress among Chinese people in the COVID-19 epidemic:

Implications and policy recommendations. General Psychiatry, 33(2), e100213. https://doi.org/10.1136/gpsych-2020-100213

Peterson, C. C. (2013). Looking forward through the lifespan: Developmental psychology. (6th ed.). Pearson.

Podsakoff, P. M., MacKenzie, S. B., Lee, J. Y., \& Podsakoff, N. P. (2003). Common method biases in behavioral research: A critical review of the literature and recommended remedies. Journal of Applied Psychology, 88(5), 879. https://doi.org/10.1037/00219010.88 .5 .879

Rutter, L. A., \& Brown, T. A. (2017). Psychometric properties of the Generalized Anxiety Disorder Scale-7 (GAD-7) in outpatients with anxiety and mood disorders. Journal of Psychopathology and Behavioral Assessment, 39(1), 140-146.

https://doi.org/10.1007/s10862-016-9571-9

Salk, R. H., Hyde, J. S., \& Abramson, L. Y. (2017). Gender differences in depression in representative national samples: Meta-analyses of diagnoses and symptoms. Psychological Bulletin, 143(8), 783-822. https://doi.org/10.1037/bul0000102

Sheldon, K. M., \& Lyubomirsky, S. (2006). How to increase and sustain positive emotion: The effects of expressing gratitude and visualizing best possible selves. The Journal of Positive Psychology, 1(2), 73-82.

Shevlin, M., McBride, O., Murphy, J., Gibson Miller, J., Hartman, T., \& Levita, L. et al. (2020). Anxiety, depression, traumatic stress, and COVID-19 related anxiety in the 
UK general population during the COVID-19 pandemic.

https://doi.org/10.31234/osf.io/hb6nq

Sigdel, A., Bista, A., Bhattarai, N., Poon, B., Giri, G., Marqusee, H., \& Thapa, S. (2020).

Depression, anxiety and depression-anxiety comorbidity amid COVID-19 pandemic:

An online survey conducted during lockdown in Nepal.

https://doi.org/10.1101/2020.04.30.20086926

Sønderskov, K., Dinesen, P., Santini, Z., \& Østergaard, S. (2020). The depressive state of Denmark during the COVID-19 pandemic. Acta Neuropsychiatrica, 1-3. https://doi.org/10.1017/neu.2020.15

Terpstra, T. J. (1952). The asymptotic normality and consistency of Kendall's test against trend, when ties are present in one ranking. Indagationes Mathematicae, 14(3), 327333. https://doi.org/10.1016/S1385-7258(52)50043-X

Tian, F., Li, H., Tian, S., Yang, J., Shao, J., \& Tian, C. (2020). Psychological symptoms of ordinary Chinese citizens based on SCL-90 during the level I emergency response to COVID-19. Psychiatry Research, 112992.

https://doi.org/10.1016/j.psychres.2020.112992.

Traunmüller, C., Stefitz, R., Gaisbachgrabner K., \& Schwerdtfeger, A. (2020). Psychological correlates of COVID-19 pandemic in the Austrian population, 22 May 2020, PREPRINT (Version 1). Research Square. https://doi.org/10.21203/rs.3.rs-23337/v1

Vaillant, G. E. (2012). Triumphs of experience: The men of the Harvard Grant Study. Belknap Press of Harvard University Press. https://doi.org/10.4159/harvard.9780674067424

Wang, C., Pan, R., Wan, X., Tan, Y., Xu,L., Ho, C., \& Ho, R. (2020). Immediate psychological responses and associated factors during the initial stage of the 2019 coronavirus disease (COVID-19) epidemic among the general population in China. 
International Journal of Environmental Research and Public Health, 17(5), 1729. https://doi.org/10.3390/ijerph17051729

Wang, C., Pan, R., Wan, X., Tan, Y., Xu, L., McIntyre, R. S., Choo, F. N., Tran, B., Ho, R., Sharma, V. K., \& Ho, C. A. (2020). Longitudinal study on the mental health of general population during the COVID-19 epidemic in China. Brain, Behavior, and Immunity. https://doi.org/10.1016/j.bbi.

Wojcik, S., Hovasapian, A., Graham, J., Motyl, M., \& Ditto, P. (2015). Conservatives report, but liberals display, greater happiness. Science, 347(6227), 1243-1246. https://doi.org/10.1126/science.1260817.

World Health Organization. (2017). Depression and other common mental disorders: Global health estimates. (No. WHO/MSD/MER/2017.2): World Health Organization.

Wu, B. (2020). Social isolation and loneliness among older adults in the context of COVID19: A global challenge. Global Health Research and Policy, 5(1), 1-3. https://doi.org/10.1186/s41256-020-00154-3 
Table 1. Sociodemographic characteristic of the four age groups.

\begin{tabular}{|c|c|c|c|c|c|c|c|c|c|c|c|c|c|}
\hline \multirow{3}{*}{ Variable } & \multirow{3}{*}{ Category } & \multicolumn{8}{|c|}{ Age groups } & \multirow{3}{*}{$\chi^{2}$} & \multirow{3}{*}{$\mathrm{p}$} & \multirow{3}{*}{ Cramér's V } & \multirow{3}{*}{$\begin{array}{c}\text { Significant } \\
\text { differences } \\
\text { between the } \\
\text { groups }\end{array}$} \\
\hline & & \multicolumn{2}{|c|}{$\begin{array}{c}(\mathrm{N}=253) \\
{[1]}\end{array}$} & \multicolumn{2}{|c|}{$\begin{array}{c}30-44 \\
(\mathrm{~N}=295) \\
{[2]}\end{array}$} & \multicolumn{2}{|c|}{$\begin{array}{c}45-59 \\
(\mathrm{~N}=320) \\
{[3]}\end{array}$} & \multicolumn{2}{|c|}{$\begin{array}{c}60-85 \\
(\mathrm{~N}=247) \\
{[4]}\end{array}$} & & & & \\
\hline & & $\mathrm{N}$ & $\%$ & $\mathrm{~N}$ & $\%$ & $\mathrm{~N}$ & $\%$ & $\mathrm{~N}$ & $\%$ & & & & \\
\hline \multirow{2}{*}{ Gender } & Female & 133 & $52.6 \%$ & 134 & $45.4 \%$ & 169 & $52.8 \%$ & 127 & $51.4 \%$ & \multirow{2}{*}{4.24} & \multirow{2}{*}{0.236} & \multirow{2}{*}{-} & \multirow{2}{*}{-} \\
\hline & Male & 120 & $47.4 \%$ & 161 & $54.6 \%$ & 151 & $47.2 \%$ & 120 & $48.6 \%$ & & & & \\
\hline \multirow[b]{2}{*}{$\overline{ }$} & $\begin{array}{l}\text { Primary } \\
\text { education }\end{array}$ & 16 & $6.3 \%$ & 8 & $2.7 \%$ & 3 & $.9 \%$ & 7 & $2.8 \%$ & \multirow{5}{*}{56.07} & \multirow{5}{*}{.001} & \multirow{5}{*}{.22} & \multirow{5}{*}{$\begin{array}{lll}1-2 & 1-3 & 2-3\end{array}$} \\
\hline & $\begin{array}{l}\text { Vocational } \\
\text { training }\end{array}$ & 12 & $4.7 \%$ & 24 & $8.1 \%$ & 43 & $13.4 \%$ & 20 & $8.1 \%$ & & & & \\
\hline \multirow[t]{3}{*}{ Education } & $\begin{array}{l}\text { Secondary } \\
\text { education }\end{array}$ & 107 & $42.3 \%$ & 66 & $22.4 \%$ & 105 & $32.8 \%$ & 78 & $31.6 \%$ & & & & \\
\hline & $\begin{array}{l}\text { Post- } \\
\text { secondary } \\
\text { education }\end{array}$ & 24 & $9.5 \%$ & 32 & $10.8 \%$ & 27 & $8.4 \%$ & 29 & $11.7 \%$ & & & & \\
\hline & $\begin{array}{l}\text { University } \\
\text { degree }\end{array}$ & 94 & $37.2 \%$ & 165 & $55.9 \%$ & 142 & $44.4 \%$ & 113 & $45.7 \%$ & & & & \\
\hline \multirow{3}{*}{$\begin{array}{c}\text { Marital } \\
\text { status }\end{array}$} & Single & 88 & $34.8 \%$ & 55 & $18.6 \%$ & 32 & $10.0 \%$ & 10 & $4.0 \%$ & \multirow[t]{3}{*}{362.02} & \multirow[t]{3}{*}{.001} & \multirow[t]{3}{*}{.50} & \multirow{3}{*}{$\begin{array}{llll}1-2 & 1-3 & 1-4 \\
2-3 & 2-4 & 3 & -4\end{array}$} \\
\hline & $\begin{array}{l}\text { Non- } \\
\text { marriage } \\
\text { relationship }\end{array}$ & 116 & $45.8 \%$ & 69 & $23.4 \%$ & 45 & $14.1 \%$ & 10 & $4.0 \%$ & & & & \\
\hline & Married & 47 & $18.6 \%$ & 157 & $53.2 \%$ & 207 & $64.7 \%$ & 170 & $68.8 \%$ & & & & \\
\hline
\end{tabular}




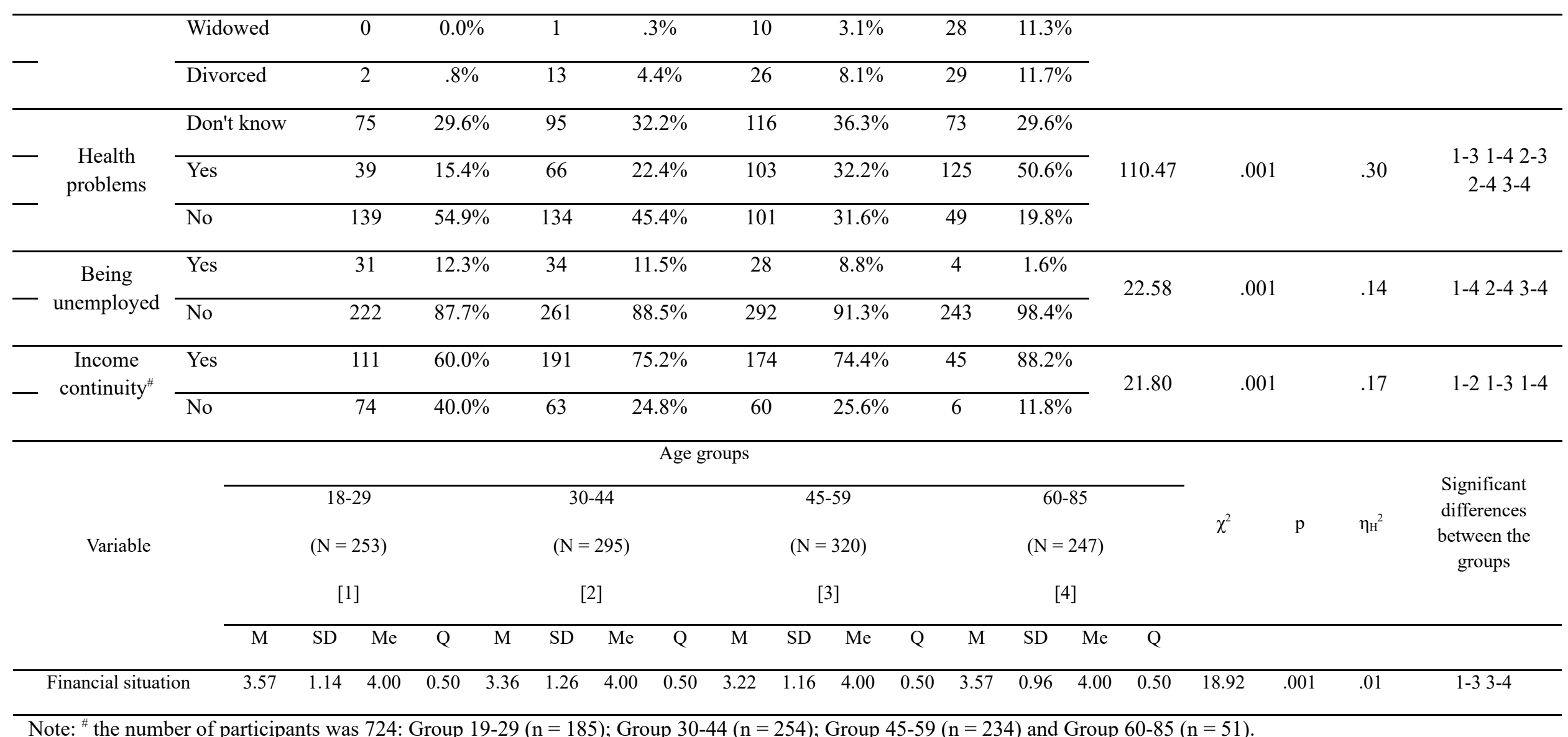


Table 2. Differences in depressive and anxiety symptoms across the four age groups Age groups

\begin{tabular}{|c|c|c|c|c|c|c|c|c|}
\hline & $\begin{array}{c}18-29 \\
\text { years } \\
(\mathrm{N}=253) \\
{[1]}\end{array}$ & $\begin{array}{c}30-44 \\
\text { years } \\
(\mathrm{N}=295) \\
{[2]}\end{array}$ & $\begin{array}{c}45-59 \\
\text { years } \\
(\mathrm{N}=320) \\
{[3]}\end{array}$ & $\begin{array}{c}60-85 \\
\text { years } \\
(\mathrm{N}=247) \\
{[4]}\end{array}$ & $\mathrm{F}$ & $\mathrm{p}$ & $\eta_{\mathrm{p}}^{2}$ & $\begin{array}{c}\text { Significant } \\
\text { differences between } \\
\text { the groups }\end{array}$ \\
\hline & $\mathrm{SD}$ & SD & SD & SD & & & & \\
\hline Anxiety symptoms & 5.39 & 5.16 & 4.86 & 5.35 & 10.86 & $<0.001$ & 0.03 & $1-3,1-4,2-4$ \\
\hline Depressive symptoms & $\begin{array}{ll}10.24 & 6.16\end{array}$ & 5.88 & 7.15 & 6.59 & 20.48 & $<0.001$ & 0.05 & $1-2,1-3,1-4,2-4$ \\
\hline
\end{tabular}


Table 3. Differences in epidemic-related variables across the four groups

\begin{tabular}{|c|c|c|c|c|c|c|c|c|c|c|c|c|c|c|c|c|c|c|c|c|c|c|c|}
\hline \multirow{4}{*}{ SERD } & \multirow{4}{*}{$\begin{array}{l}\text { What extent each of the following } \\
\text { is currently a problem for you? }\end{array}$} & \multicolumn{16}{|c|}{ Age groups } & \multirow{4}{*}{$\chi^{2}$} & \multirow{4}{*}{$\mathrm{p}$} & \multirow{4}{*}{$\eta_{H^{2}}^{2}$} & \multirow{4}{*}{$\begin{array}{l}\text { Significant } \\
\text { differences } \\
\text { between the } \\
\text { groups }\end{array}$} & \multirow{2}{*}{\multicolumn{2}{|c|}{ Jonckheere-Terpstra Tes }} \\
\hline & & \multirow{2}{*}{\multicolumn{4}{|c|}{$\begin{array}{c}18-29 \\
(\mathrm{~N}=253) \\
{[1]}\end{array}$}} & \multirow{2}{*}{\multicolumn{3}{|c|}{$\begin{array}{c}30-44 \\
(\mathrm{~N}=295) \\
{[2]}\end{array}$}} & & \multirow{2}{*}{\multicolumn{3}{|c|}{$\begin{array}{c}45-59 \\
(\mathrm{~N}=320) \\
{[3]}\end{array}$}} & \multirow{2}{*}{\multicolumn{5}{|c|}{$\begin{array}{c}60-85 \\
(\mathrm{~N}=247) \\
{[4]}\end{array}$}} & & & & & & \\
\hline & & & & & & & & & & & & & & & & & & & & & & & \\
\hline & & $\mathrm{M}$ & SD & $\mathrm{Me}$ & $\mathrm{Q}$ & $\mathrm{M}$ & SD & $\mathrm{Me}$ & $\mathrm{Q}$ & $\mathrm{M}$ & SD & $\mathrm{Me}$ & $\mathrm{Q}$ & $\mathrm{M}$ & SD & $\mathrm{Me}$ & $\mathrm{Q}$ & & & & & $\mathrm{z}$ & $\mathrm{p}$ \\
\hline \multirow{5}{*}{ RDH } & $\begin{array}{l}\text { Difficult relationships at home } \\
\text { (feeling that we "act on our } \\
\text { nerves", quarrels, etc.) }\end{array}$ & 2.35 & 0.91 & 2.00 & 0.50 & 2.28 & 0.94 & 2.00 & 0.50 & 2.05 & 0.89 & 2.00 & 1.00 & 1.98 & 0.86 & 2.00 & 1.00 & 30.41 & .001 & .02 & $1-31-42-32-4$ & -5.34 & .001 \\
\hline & $\begin{array}{l}\text { Inability to stay alone (without } \\
\text { other people) }\end{array}$ & 2.35 & 0.98 & 2.00 & 0.50 & 2.21 & 0.88 & 2.00 & 0.50 & 2.00 & 0.81 & 2.00 & 0.50 & 1.90 & 0.84 & 2.00 & 0.50 & 37.16 & .001 & .03 & $1-31-42-32-4$ & -6.14 & .001 \\
\hline & Increased number of daily duties & 2.30 & 0.83 & 2.00 & 0.50 & 2.24 & 0.83 & 2.00 & 0.50 & 2.09 & 0.76 & 2.00 & 0.50 & 1.96 & 0.70 & 2.00 & 0.50 & 28.04 & .001 & .02 & $1-31-42-4$ & -5.24 & .001 \\
\hline & $\begin{array}{l}\text { Loneliness, a feeling of being } \\
\text { abandoned }\end{array}$ & 2.44 & 0.96 & 2.00 & 0.50 & 2.27 & 0.89 & 2.00 & 0.50 & 2.16 & 0.83 & 2.00 & 0.50 & 2.22 & 0.85 & 2.00 & 0.50 & 14.41 & .002 & .01 & $1-31-4$ & -3.08 & .002 \\
\hline & Total & 2.36 & 0.66 & 2.50 & 0.38 & 2.25 & 0.69 & 2.25 & 0.50 & 2.08 & 0.63 & 2.00 & 0.38 & 2.01 & 0.62 & 2.00 & 0.5 & 47.79 & .001 & .04 & $1-3$ 1-4 2-3 2-4 & -6.82 & .001 \\
\hline \multirow{4}{*}{ ERDP } & $\begin{array}{l}\text { Feeling that my freedom as a } \\
\text { human is restricted (e.g. deciding } \\
\text { for myself) }\end{array}$ & 2.75 & 0.88 & 3.00 & 0.50 & 2.81 & 0.80 & 3.00 & 0.50 & 2.72 & 0.85 & 3.00 & 0.50 & 2.74 & 0.88 & 3.00 & 0.50 & 1.58 & .664 & - & - & -0.58 & .559 \\
\hline & $\begin{array}{l}\text { Change in the way of shopping } \\
\text { due to new regulations (e.g. } \\
\text { reduced number of people in a } \\
\text { store, the need to shop online) }\end{array}$ & 2.43 & 0.87 & 2.00 & 0.50 & 2.47 & 0.86 & 3.00 & 0.50 & 2.34 & 0.78 & 2.00 & 0.50 & 2.37 & 0.88 & 2.00 & 0.50 & 5.13 & .162 & - & - & -1.61 & .107 \\
\hline & $\begin{array}{l}\text { Wearing face masks in public } \\
\text { places }\end{array}$ & 2.76 & 0.98 & 3.00 & 1.00 & 2.83 & 0.94 & 3.00 & 1.00 & 2.63 & 0.97 & 3.00 & 0.50 & 2.76 & 1.00 & 3.00 & 1.00 & 6.51 & .089 & - & - & -1.02 & .308 \\
\hline & Total & 2.65 & 0.70 & 2.67 & 0.33 & 2.70 & 0.68 & 2.67 & 0.33 & 2.56 & 0.66 & 2.67 & 0.50 & 2.62 & 0.72 & 2.67 & 0.5 & 7.02 & .071 & - & - & -1.46 & .145 \\
\hline \multirow{3}{*}{ LSC } & $\begin{array}{l}\text { No meetings with beloved ones } \\
\text { and friends }\end{array}$ & 2.80 & 0.93 & 3.00 & 1.00 & 2.60 & 0.87 & 3.00 & 0.50 & 2.63 & 0.87 & 3.00 & 0.50 & 2.83 & 0.90 & 3.00 & 0.50 & 15.09 & .002 & .01 & $1-22-43-4$ & 0.46 & .649 \\
\hline & $\begin{array}{l}\text { No meetings with people in } \\
\text { general }\end{array}$ & 2.68 & 0.92 & 3.00 & 0.50 & 2.52 & 0.88 & 3.00 & 0.50 & 2.53 & 0.86 & 3.00 & 0.50 & 2.72 & 0.85 & 3.00 & 0.50 & 10.95 & .012 & .01 & - & 0.39 & .694 \\
\hline & Total & 2.74 & 0.83 & 3.00 & 0.50 & 2.56 & 0.80 & 2.50 & 0.50 & 2.58 & 0.81 & 2.50 & 0.50 & 2.77 & 0.81 & 3.00 & 0.75 & 14.37 & .002 & .01 & $2-43-4$ & 0.51 & .612 \\
\hline
\end{tabular}




\begin{tabular}{|c|c|c|c|c|c|c|c|c|c|c|c|c|c|c|c|c|c|c|c|c|c|c|c|}
\hline \multirow{3}{*}{ FURSV } & $\begin{array}{l}\text { Feeling of uncertainty, } \\
\text { unpredictability of the situation }\end{array}$ & 2.73 & 0.85 & 3.00 & 0.50 & 2.78 & 0.77 & 3.00 & 0.50 & 2.78 & 0.72 & 3.00 & 0.50 & 2.78 & 0.79 & 3.00 & 0.50 & 0.31 & .959 & - & - & 0.31 & .756 \\
\hline & $\begin{array}{l}\text { Feeling of danger, anxiety } \\
\text { associated with the spread of the } \\
\text { virus }\end{array}$ & 2.51 & 0.87 & 2.00 & 0.50 & 2.62 & 0.82 & 3.00 & 0.50 & 2.66 & 0.82 & 3.00 & 0.50 & 2.85 & 0.81 & 3.00 & 0.50 & 21.84 & .001 & .02 & $1-42-43-4$ & 4.46 & .001 \\
\hline & Total & 2.62 & 0.73 & 2.50 & 0.50 & 2.70 & 0.69 & $\mathbf{3 . 0 0}$ & 0.50 & 2.72 & 0.66 & $\mathbf{3 . 0 0}$ & 0.25 & 2.81 & 0.73 & $\mathbf{3 . 0 0}$ & 0.25 & 9.62 & .012 & .01 & $1-4$ & 2.96 & .003 \\
\hline \multicolumn{2}{|c|}{ Restriction in moving around and traveling } & 2.81 & 0.88 & 3.00 & 0.50 & 2.80 & 0.85 & 3.00 & 0.50 & 2.71 & 0.85 & 3.00 & 0.50 & 2.85 & 0.89 & 3.00 & 1.00 & 4.89 & .180 & - & - & -0.06 & .951 \\
\hline \multicolumn{2}{|c|}{ Boredom, monotony } & 2.68 & 0.91 & 3.00 & 0.50 & 2.43 & 0.90 & 2.00 & 0.50 & 2.31 & 0.88 & 2.00 & 0.50 & 2.30 & 0.85 & 2.00 & 0.50 & 29.42 & .001 & .02 & $1-21-31-4$ & -4.97 & .001 \\
\hline \multicolumn{2}{|c|}{ The need to change my lifestyle } & 2.54 & 0.86 & 2.00 & 0.50 & 2.48 & 0.84 & 2.00 & 0.50 & 2.45 & 0.79 & 2.00 & 0.50 & 2.41 & 0.84 & 2.00 & 0.50 & 2.32 & .508 & - & - & -1.51 & .132 \\
\hline \multicolumn{2}{|c|}{ Feeling tired of this whole situation } & 2.85 & 0.86 & 3.00 & 0.75 & 2.81 & 0.82 & 3.00 & 0.50 & 2.76 & 0.82 & 3.00 & 0.50 & 2.79 & 0.80 & 3.00 & 0.50 & 1.55 & .670 & - & - & -1.02 & .306 \\
\hline \multicolumn{2}{|c|}{$\begin{array}{l}\text { Feeling lost in the recommendations and } \\
\text { restrictions (e.g. getting lost in what you can } \\
\text { and cannot do) }\end{array}$} & 2.57 & 0.88 & 3.00 & 0.50 & 2.37 & 0.85 & 2.00 & 0.50 & 2.27 & 0.80 & 2.00 & 0.50 & 2.22 & 0.82 & 2.00 & 0.50 & 26.18 & 0.001 & .02 & $1-31-4$ & -4.98 & .001 \\
\hline
\end{tabular}

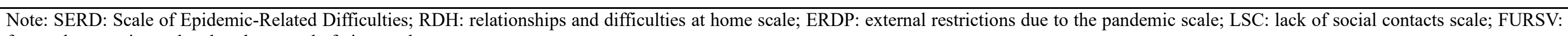
fear and uncertainty related to the spread of virus scale; 
Table 4. Univariate effects of demographic variables on anxiety and depressive symptoms in four age groups.

\begin{tabular}{|c|c|c|c|c|c|c|c|c|c|c|c|c|c|c|c|c|}
\hline \multirow{3}{*}{ Age group } & \multicolumn{8}{|c|}{ Anxiety symptoms } & \multicolumn{8}{|c|}{ Depressive symptoms } \\
\hline & \multicolumn{2}{|c|}{$18-29$} & \multicolumn{2}{|c|}{$30-44$} & \multicolumn{2}{|c|}{$45-59$} & \multicolumn{2}{|l|}{$60-85$} & \multicolumn{2}{|c|}{$18-29$} & \multicolumn{2}{|c|}{$30-44$} & \multicolumn{2}{|c|}{$45-59$} & \multicolumn{2}{|l|}{$60-85$} \\
\hline & $B$ & $S E$ & $B$ & $S E$ & $B$ & $S E$ & $B$ & $S E$ & $B$ & $S E$ & $B$ & $S E$ & $B$ & $S E$ & $B$ & $S E$ \\
\hline \multicolumn{17}{|l|}{ Gender: } \\
\hline Female & 1.34 & .68 & 0.22 & .61 & 0.70 & .54 & $1.88^{* *}$ & .67 & $-1.57 *$ & .77 & -.79 & .69 & -.48 & .61 & $-1.37^{*}$ & .67 \\
\hline \multicolumn{17}{|l|}{ Male- reference } \\
\hline \multicolumn{17}{|l|}{ Education: } \\
\hline Primary education & 0.38 & 1.46 & $4.29^{*}$ & 1.86 & -1.82 & 2.84 & -2.01 & 2.08 & -.26 & 1.59 & 2.27 & 2.11 & -1.84 & 3.17 & -2.82 & 2.01 \\
\hline Vocational training & -1.83 & 1.65 & .21 & 1.12 & .54 & .85 & 1.22 & 1.29 & $-4.27 *$ & 1.80 & 1.09 & 1.25 & 1.19 & .89 & -1.57 & 1.23 \\
\hline Secondary education & 1.08 & .76 & -.85 & .75 & .43 & .63 & 1.45 & .79 & $2.06^{* *}$ & .77 & .18 & .82 & -.54 & .65 & 1.79 & .72 \\
\hline $\begin{array}{l}\text { Post-secondary } \\
\text { education }\end{array}$ & .51 & 1.23 & -.62 & .99 & 1.18 & 1.02 & 1.35 & 1.11 & 1.07 & 1.32 & -.57 & 1.10 & 1.01 & 1.09 & 1.28 & 1.04 \\
\hline \multicolumn{17}{|l|}{$\begin{array}{l}\text { University degree - } \\
\text { reference }\end{array}$} \\
\hline \multicolumn{17}{|l|}{ Marital status: } \\
\hline $\begin{array}{l}\text { Non-marriage } \\
\text { relationship }\end{array}$ & .62 & .68 & .08 & 71 & -.62 & .77 & .06 & 1.73 & .46 & .78 & .56 & .81 & -.38 & .86 & .73 & 1.71 \\
\hline
\end{tabular}




\begin{tabular}{|c|c|c|c|c|c|c|c|c|c|c|c|c|c|c|c|c|}
\hline Married & -.43 & .87 & -.52 & .60 & -.78 & .57 & .05 & .74 & -.66 & .99 & -1.19 & .68 & -.75 & .64 & -.02 & .73 \\
\hline Divorced & -1.70 & 3.83 & .99 & 1.47 & .45 & .99 & -1.02 & 1.06 & -2.26 & 4.38 & .23 & 1.67 & -.84 & 1.12 & -1.03 & 1.04 \\
\hline Widowed & - & - & .41 & 5.18 & 1.36 & 1.56 & .93 & 1.57 & - & - & -.16 & 5.89 & 2.93 & 1.74 & .98 & 1.06 \\
\hline \multicolumn{17}{|l|}{ Single - reference } \\
\hline \multicolumn{17}{|l|}{ Health problems: } \\
\hline Don't know & $1.60^{*}$ & .77 & $1.98^{* *}$ & .68 & $1.65^{*}$ & .65 & 0.64 & .98 & 1.51 & .84 & 1.19 & .73 & 1.07 & .63 & .34 & .74 \\
\hline Yes & 1.72 & .97 & $-2.56^{* *}$ & .76 & $2.20^{* *}$ & .67 & $2.08^{*}$ & .89 & 1.99 & 1.07 & $2.46^{* *}$ & .81 & 1.06 & .65 & .77 & .67 \\
\hline \multicolumn{17}{|l|}{ No - reference } \\
\hline Income continuity & $-1.96^{* *}$ & .82 & -0.88 & .73 & -0.68 & .73 & 0.10 & 2.26 & $-2.09 *$ & .91 & -1.56 & .86 & -.99 & .83 & -1.44 & 2.34 \\
\hline Financial situation & $-0.78^{* *}$ & .29 & -0.15 & .24 & $-0.66^{* *}$ & .23 & $-1.22^{* * *}$ & .35 & -.25 & .34 & .06 & .27 & -.33 & .26 & $-.98^{* *}$ & .35 \\
\hline Being unemployed & 1.53 & 1.03 & 1.03 & .94 & 1.57 & .96 & -3.81 & 2.69 & 1.64 & 1.18 & 2.04 & 1.07 & 1.20 & 1.08 & -.09 & 2.67 \\
\hline Being student & 0.26 & .76 & - & - & - & - & - & - & & .53 & .86 & & & - & & - \\
\hline
\end{tabular}


Table 5. Univariate effects of Covid-19-related variables on anxiety and depressive symptoms in four age groups.

\begin{tabular}{|c|c|c|c|c|c|c|c|c|c|c|c|c|c|c|c|c|}
\hline \multirow{3}{*}{ Age group } & \multicolumn{8}{|c|}{ Anxiety symptoms } & \multicolumn{8}{|c|}{ Depressive symptoms } \\
\hline & \multicolumn{2}{|c|}{$18-29$} & \multicolumn{2}{|c|}{$30-44$} & \multicolumn{2}{|c|}{$45-59$} & \multicolumn{2}{|c|}{$60-85$} & \multicolumn{2}{|c|}{$18-29$} & \multicolumn{2}{|l|}{$30-44$} & \multicolumn{2}{|c|}{$45-59$} & \multicolumn{2}{|l|}{$60-85$} \\
\hline & $B$ & $S E$ & $B$ & $S E$ & $B$ & $S E$ & $B$ & $S E$ & $B$ & $S E$ & $B$ & $S E$ & $B$ & $S E$ & $B$ & $S E$ \\
\hline Social support & 0.25 & .47 & -.70 & .41 & -0.50 & .35 & $0.88^{*}$ & .43 & -.53 & .54 & -.87 & .47 & $-.79^{*}$ & .39 & .15 & .43 \\
\hline $\begin{array}{l}\text { Perceived health } \\
\text { and life risk of } \\
\text { COVID-19 }\end{array}$ & $1.19^{* *}$ & .40 & $1.51^{* * *}$ & .34 & $1.77^{* * *}$ & .31 & $1.65^{* * *}$ & .39 & $1.47^{* * *}$ & .45 & $1.76^{* *}$ & .38 & $1.61^{* * *}$ & .35 & $1.06^{* * *}$ & .39 \\
\hline $\begin{array}{l}\text { Lack of social } \\
\text { contacts }\end{array}$ & $1.56^{* * *}$ & .40 & $1.10^{* *}$ & .37 & 0.45 & .34 & $2.33^{* * *}$ & .39 & $1.67^{* * *}$ & .45 & .74 & .43 & .58 & .37 & $1.39^{* * *}$ & .40 \\
\hline $\begin{array}{l}\text { Difficulties in } \\
\text { relationships and } \\
\text { at home }\end{array}$ & $3.51^{* * *}$ & .47 & $3.22^{* * *}$ & .39 & $2.91^{* * *}$ & .40 & $3.26^{* * *}$ & .51 & $4.30^{* * *}$ & .53 & $3.10^{* *}$ & .46 & $3.33^{* * *}$ & .45 & $3.29^{* * *}$ & .51 \\
\hline $\begin{array}{l}\text { External } \\
\text { restrictions }\end{array}$ & $2.25^{* * *}$ & .47 & $1.27^{* *}$ & .44 & $.96^{*}$ & .41 & $2.49^{* * *}$ & .45 & $2.67^{* * *}$ & .53 & $1.45^{* *}$ & .49 & $1.03^{*}$ & .46 & $2.14^{* * *}$ & .45 \\
\hline $\begin{array}{l}\text { Fear and } \\
\text { uncertainty }\end{array}$ & $1.97^{* * *}$ & .45 & $2.75^{* * *}$ & .41 & $2.86^{* * *}$ & .38 & $3.49^{* * *}$ & .41 & $2.33^{* * *}$ & .51 & $2.27^{* * *}$ & .47 & $2.80^{* * *}$ & .44 & $2.52^{* * *}$ & .43 \\
\hline
\end{tabular}


Table 6. Epidemic-related variables regressed on anxiety and depressive symptoms in four age groups

\begin{tabular}{|c|c|c|c|c|c|c|c|c|c|c|c|c|c|c|c|c|}
\hline \multirow{3}{*}{ Age group } & \multicolumn{8}{|c|}{ Anxiety symptoms } & \multicolumn{8}{|c|}{ Depressive symptoms } \\
\hline & \multicolumn{2}{|c|}{$18-29$} & \multicolumn{2}{|c|}{$30-44$} & \multicolumn{2}{|c|}{$45-59$} & \multicolumn{2}{|l|}{$60-85$} & \multicolumn{2}{|c|}{$18-29$} & \multicolumn{2}{|c|}{$30-44$} & \multicolumn{2}{|c|}{$45-59$} & \multicolumn{2}{|c|}{$60-85$} \\
\hline & $B$ & $S E$ & $B$ & $S E$ & $B$ & $S E$ & $B$ & $S E$ & $B$ & $S E$ & $B$ & $S E$ & $B$ & $S E$ & $B$ & $S E$ \\
\hline Social support & 0.47 & .45 & $-1.01^{* *}$ & .38 & -0.43 & .32 & 0.20 & .39 & -0.26 & .50 & $-0.98^{*}$ & .45 & -0.72 & .37 & -0.26 & .40 \\
\hline $\begin{array}{l}\text { Perceived health } \\
\text { and life risk of } \\
\text { COVID-19 }\end{array}$ & 0.37 & .40 & $0.80^{*}$ & .33 & $0.83^{*}$ & .33 & 0.60 & .38 & 0.48 & .45 & $1.36^{* *}$ & .39 & 0.66 & .38 & 0.36 & .39 \\
\hline $\begin{array}{l}\text { Lack of social } \\
\text { contacts }\end{array}$ & -0.09 & .48 & -0.62 & .43 & $-0.95^{* *}$ & .36 & 0.65 & .43 & -0.22 & .53 & $-1.22^{*}$ & .50 & -0.80 & .41 & -0.05 & .45 \\
\hline $\begin{array}{l}\text { Difficulties in } \\
\text { relationships } \\
\text { and at home }\end{array}$ & $2.92^{* * * *}$ & .59 & $2.62^{* * * *}$ & .50 & $2.44^{* * *}$ & .45 & $1.98^{* * *}$ & .51 & $3.50^{* * *}$ & .66 & $2.85^{* * *}$ & .59 & $2.95^{* * *}$ & .52 & $2.43^{* * *}$ & .53 \\
\hline $\begin{array}{l}\text { External } \\
\text { restrictions }\end{array}$ & $1.17^{*}$ & .54 & 0.02 & .45 & -0.26 & .43 & 0.63 & .48 & $1.40^{*}$ & .60 & 0.65 & .53 & -0.43 & .49 & 0.72 & .51 \\
\hline $\begin{array}{l}\text { Fear and } \\
\text { uncertainty }\end{array}$ & 0.12 & .53 & $1.54^{* *}$ & .46 & $1.96^{* * *}$ & .48 & $1.99^{* * *}$ & .53 & 0.25 & .59 & 0.75 & .54 & $1.81^{* *}$ & .54 & $1.50^{* *}$ & .56 \\
\hline $\mathbf{R}^{2}$ & .21 & & .26 & & .26 & & .31 & & .24 & & .21 & & .23 & & .22 & \\
\hline $\mathbf{F}$ & $10.85^{* * *}$ & & $16.84^{* * *}$ & & $17.81^{* * *}$ & & $17.59^{* * *}$ & & $12.60^{* * *}$ & & $12.52^{* * *}$ & & $15.10^{* * *}$ & & $11.03^{* * *}$ & \\
\hline
\end{tabular}




\section{Supplementary Material (SM)}

\section{Factor Analysis}

Before conducting the factor analysis, we verified that the data was suitable for it. The Kaiser-Meyer-Olkin measure of .92 was high and Bartlett's test of sphericity was significant, Chi2 $(136)=7331.91, p<.001$. Thus, the data was adequate for factor analysis. We conducted an exploratory factor analysis with an oblique (oblimin) rotation first and examined the component correlation matrix. As the correlations between the components were not particularly high (.24-.44), we used the varimax rotation in the main analysis. Results of this analysis showed that eigenvalue was greater than 1.0 for four factors; the scree plot also suggested four factors. These four factors explained $62 \%$ of the total variance. We omitted the questions with high cross-loadings and included in our subscales only these where the difference was at least of .20 (Table 1 SM).

Table 1 SM. Factor Loadings from an Exploratory Factor Analysis of the Difficulties Related to the Pandemic.

\section{Component}

$\begin{array}{llll}1 & 2 & 3 & 4\end{array}$

Difficult relationships at home (feeling that we "act on our $\quad \mathbf{0 . 7 6}$ nerves", quarrels, etc.)

Inability to stay alone (without other people) 
Feeling lost in the recommendations and restrictions (e.g. getting 0.54

lost in what you can and cannot do)

No meetings with beloved ones and friends

0.82

No meetings with people in general

0.82

Boredom, monotony

$0.45 \quad 0.55$

Restriction in moving around and traveling

$0.53 \quad 0.51$

Wearing face masks in public places

0.78

Change in the way of shopping due to new regulations (e.g.

0.39

0.66

reduced number of people in a store, the need to shop online)

Feeling that my freedom as a human is restricted (e.g. deciding for myself)

$0.36 \mathbf{0 . 6 4}$

The need to change my lifestyle

$\begin{array}{llll}0.39 & 0.38 & 0.40 & 0.30\end{array}$

Feeling of danger, anxiety associated with the spread of the virus

0.82

Feeling of uncertainty, unpredictability of the situation

0.79

Feeling tired of this whole situation

$\begin{array}{lll}0.34 & 0.40 & 0.52\end{array}$

Note: Method was a principal component analysis and varimax rotation with Kaiser normalization. Values smaller than \pm .30 are not presented. Items in grey were not included in the subscales due to high cross-loadings. 